\title{
Editorial
}

\section{A Human Rights Emergency in Mental Health}

Can 'new governance' Mechanisms in the EU Make a Difference?

On the 1oth October 2019, Ed Sheeran and Prince Harry made headlines for pledging their support to 'World Mental Health Day' - an international day dedicated to mental health education, awareness and advocacy against stigma. Leaving aside one's views on the monarchy and popular musicians, the message they were delivering is a serious and urgent one. Moreover, it is a message human rights lawyers and EU policy makers need to deliver too. There are, arguably, three core reasons for this.

The first is high prevalence and cost. According to the World Health Organisation (WHO), mental health problems affect one in four citizens at least once during their lifetime and can affect more than $10 \%$ of the EU population (i.e. 50 million people) during any given year. ${ }^{2}$ According to Eurostat, suicide remains a significant cause of premature death in Europe, with over 50,000 deaths a year in the EU. ${ }^{3}$ Aside from human suffering, mental health problems cost $€ 26$ o billion a year due to lower employment and productivity rates across the 28 EU member states. ${ }^{4}$

The second is low investment. Despite the human and economic costs, public spending via health budgets on mental health are negligible in comparison

1 Newsbeat, 2019. 'Ed Sheeran and Prince Harry team up for World Mental Health Day.' в BC News, 10 October. Retrieved on 10 October 2019, https://www.bbc.co.uk/news/newsbeat-50000494.

2 WHo Regional Office for Europe, 'Adolescent mental health in the European Region', Factsheet for World Mental Health Day 2018. Retrieved on 11 October 2019, http://www.euro.who .int/_data/assets/pdf_file/ooo5/383891/adolescent-mh-fs-eng.pdf?ua=1.

3 Eurostat, Causes of death - standardised death rate by residence (20/09/2019).

4 OECD/EU, Health at a Glance: Europe 2018: State of Health in the EU Cycle (Paris: OECD Publishing, 2018). 
with other public health issues (cardio-vascular diseases, cancers, pharmaceutical interventions, etc.). Only seven percent of health budgets are allocated to address mental health. ${ }^{5}$ In the UK mental health research in 2018 received 25 times less funding, per person affected, than physical conditions such as cancer. ${ }^{6}$ Worse still, almost one third of countries have no specific budget allocated at all to mental health. ${ }^{7}$

The third is negative predictions. A recent OECD report concluded that mental disorders account 'for the fastest growing categories of the burden of disease with which health systems must cope.8 ${ }^{8}$ The WHO reported, based on Disability Adjusted Life Years (DALYs), that $30 \%$ of the European population are burdened by mental disorders and self-inflicted injuries compared to cancer $(17.1 \%)$ or cardiovascular disease $(16 \%)$. The Lancet Commission estimated that mental health disorders will, if no collective response is formulated, cost the global economy up to $\$ 16$ trillion between 2010 and 2030 .

Anyone interested in human rights protection must be alarmed by these statistics. Why? Because the relationship between human rights and mental health is important. As Lawrence Gostin points out: 'coercive mental health policies infringe human rights; invasions of human rights are harmful to mental health; and positive promotion of mental health and human rights are mutually reinforcing and synergistic. ${ }^{9}$ There are numerous sources of human rights law, albeit varying in terms of content and imposition of state obligations, that uphold the right to mental health: namely, Article 25 of the

5 UN Human Rights Council, 'Report of the Special Rapporteur on the right of everyone to the enjoyment of the highest attainable standard of physical and mental health' (28 March 2017) A/HRC/35/21. Retrieved on 13 October 2019, https://www.refworld.org/docid/593947e14 .html.

6 MQ Foundation, 'UK Mental Health Research Funding 2014-2010' (2018). Retrieved on 10 October 2019, https://www.mqmentalhealth.org/articles/research-funding-landscape.

7 T. Van Bortel, 'Human Rights in Mental Health: A Global Necessity', Cambridge Institute of Public Health, University of Cambridge, Promise Global Symposium (Cambridge, 9 October 2015).

8 See n 4; see wHo (2014). 'Health statistics and information systems'. Retrieved November 2014 from http://www.who.int/healthinfo/global_burden_disease/estimates/en/index2 .html.

9 L.O. Gostin, 'Human Rights of Persons With Mental Disabilities: The European Convention of Human Rights', International Journal of Law and Psychiatry, 23(2) 2000 127; see also G. Szmukler, 'Mental health law and the UN Convention on the rights of persons with disabilities', International Journal of Law and Psychiatry 37(3) (2014) 245-252; S. Porsdam Mann, 'Human Rights-Based Approached to Mental Health: A Review of Programs', Health and Human Rights Journal 18(1) (2016) 263-276; D. Puras and P. Gooding, 'Mental health and human rights in the 21st century', World Psychiatry 18(1) (2019) 42-43. 
Universal Declaration of Human Rights, ${ }^{10}$ Article 12 of the International Covenant on Economic, Social and Cultural Rights, ${ }^{11}$ the entire UN Convention on the Rights of Persons with Disabilities, ${ }^{12}$ and various articles in the European Convention on Human Rights. ${ }^{13}$ A crisis in mental health is a crisis in human rights protection. So what can be done from a wider governance perspective to address this crisis?

One option is to look at a particular type of EU 'new governance' in health care policy: 'joint action strategies. ${ }^{14}$ These strategies are very precise policy initiatives that are funded jointly by the European Commission and by participating Member States. Key international and supranational bodies (such as the WHO, OECD, and EMCDDA) and NGOS are also welcome to participate. Joint Actions are generally funded on a 50/5o basis, although the Commission will shoulder up to $80 \%$ of the costs in 'exceptional' cases. The focus of Joint Action strategies is generally quite precise (health indicators, rare diseases, nanomaterials, congenital anomalies, organ donation, e-health governance, HIV, pharmacovigilance, alcohol use), and the topics are by their very nature more complex (chronic disease, cancer, health inequalities, health human resources). The stated objective of the Joint Action strategy is to identify common priorities between states, and to facilitate communication and coordination between them. Capacity gaps and best practices are noted, potential strategies of cooperation are discussed, and modes of operationalisation are developed. Unlike open methods of coordination (OMCs), the attempt is, as

10 Article 25 UDHR: 'Everyone has the right to a standard of living adequate for the health and well-being of himself and his family, including food, clothing, housing and medical care and necessary social services, and the right to security in the event of unemployment, sickness, disability, widowhood, old age or other lack of livelihood in circumstances beyond his control.'

11 Article 12 ICESCR states: '[T] he right of everyone to the highest attainable standard of physical and mental health.'

12 Article 1 UNCRPD states that the term 'disability' includes 'those who have long-term physical, mental, intellectual, or sensory impairments which in interaction with various barriers may hinder their full and effective participation in society on an equal basis with others.'

13 See Gostin, supra n. 9 at $133^{-158 .}$

14 See European Commission, 'Guidance on Joint Action Plans: Structural and Cohesion Funds 2014-20' (June 2015). Retrieved on 10 October 2019, https://ec.europa.eu/regional_policy/sources/docgener/informat/2014/guidance_jap_en.pdf; See K. Fierlbeck, 'The changing contours of experimental governance in European health care', Social Science and Medicine 108 (2014) 89-96; L. Senden, 'Soft Law, self-regulation and co-regulation in European Law: where do they meet?', European Journal of Comparative Law 9(1) (2005). 
one interviewee noted, to see that the EU's money is 'well spent'. The funding period is clearly limited and potential deliverables must be identified ex ante.

Any potential participant is free to submit a proposal for Joint Action funding, though many of the programmes have been initiatives led by a current Council's presidency (such as Spain's support for the health inequalities programme). Specific countries normally act as 'leads' on issues in which they are particularly interested (France and the UK have been the most active in coordinating Joint Actions), and states are free to join if they believe that a particular focus is especially relevant to their jurisdiction. The focus of the Joint Actions is more on implementing existing knowledge than producing new ideas. Rather than isolated pilot projects, Joint Actions are attempts at executing best practices across jurisdictions. Effort is made to achieve economies of scale, promotion of best practices, facilitating networks, and establishing benchmarks. The results are to be quite concrete, and are expected to be permanently institutionalized.

Against this conceptual ideal of joint action programmes, what has been done at the EU-level in relation to mental health? In 2013, the 'Joint Action on Mental Health and Well-being'15 was launched. Its objective was 'to contribute to the promotion of mental health and well-being, the prevention of mental disorders and the improvement of care and social inclusion of people with mental disorders in Europe.' It received funding from the European Agency for Health and Consumers, and involved $5^{1}$ partners representing $28 \mathrm{EU}$ Member States and 11 European organizations. ${ }^{16}$ This Action came to an end in 2016. It resulted in comprehensive recommendations in five areas: ${ }^{17}$ (i) promotion of mental health at the workplaces; (ii) promotion of mental health in schools; (iii) promoting action against depression and suicide and implementation of e-health approaches; (iv) developing community-based and socially inclusive mental health care for people with severe mental disorders; and (v) promoting the integration of mental health in all policies. Perhaps more important than these reports - which are not to be underestimated - is the parting gifts left from the Joint Action: 'The European Framework for Action on Mental Health and Wellbeing' (the Framework) and the re-launched 'EU Compass for Action on Mental Health and Wellbeing' (the Compass). The Framework is a non-binding call to action containing a large amount of evidence-based

15 EU Joint Action on Mental Health and Wellbeing 2012. Retrieved on 10 October 2019, http://www.mentalhealthandwellbeing.eu/the-joint-action/.

16 Coordinated by the Nova Medical School/Faculdade de Ciências Médicas, Nova University of Lisbon, Portugal.

17 All available at: http://www.mentalhealthandwellbeing.eu/publications/. 
recommendations and comparative reflections on the state of mental health services across the EU. It is strategic - advocating for reforms taking into account economic, social and human rights factors. The Compass is a mechanism to continuously collect, exchange, and analyse information on policy and stakeholder activities in mental health. It results in annual surveys disseminating good practices in mental health and data on member states activities. So after almost a decade of extensive 'new governance' into mental health and hundreds of reports later, what can we say about the effectiveness of this approach in dealing with the crisis?

The answer to this depends on what one considers the purpose of the Joint Action and its outputs to be. This method of governance was never going to be a quick fix solution to the mental health crisis in Europe. It is meant as a means to share information, set benchmarks, and most importantly, provide those who are arguing for policy reform with concrete expert-based alternatives. In this respect, the Joint Action has been a success. Alternatives are there and they are ready to be picked up and adopted. This does not take away from the realpolitik underlying the mental health crisis. Recommendations are useless without political will. This is the case on the national and European-level. The last concrete action taken on mental health in the European Parliament was in 2008, nearly 10 years ago. There has been no concrete follow-up in the Parliament to the Joint Action findings. Deirdre Clune, a member of the MEP coalition on mental health and wellbeing, has urged the Parliament to rectify this and has suggested a European Year of Mental Health to ensure the issue is (at least publically) placed on the legislative agenda. ${ }^{18}$ Nessa Childers, a member of the Parliament's Environment, Public Health and Food Safety Committee, believes the Compass does not go far enough - 'a more ambitious plan would include implementing mental health-specific national action plans modelled on existing cancer and rare disease plans. ${ }^{19}$

It is argued here that the new governance outputs outlined above are a foundation, at the very least, for future European-level policy-making in all areas economic and social. ${ }^{20}$ Recognising that healthcare policy remains primarily

18 D. Clune, 'EU must highlight importance of mental health in all policies', The Parliament Magazine (25 October 2017). Retrieved on 12 October 2019, https://www.theparliamentmagazine.eu/articles/opinion/eu-must-highlight-importance-mental-health-all-policies.

19 N. Childers, 'Policymakers must tackle work-related stress', The Parliament Magazine (30 April 2018). Retrieved on 12 October 2019, https://www.theparliamentmagazine.eu/ articles/opinion/policymakers-must-tackle-work-related-stress.

20 On this, see V. Andriukaitis (European health and food safety Commissioner), 'Gastein health forum: Making the case for health in all policies', The Parliament Magazine (28 September 2017). 
located within the competence of the member states, it is imperative at the EU level - to ensure real action is taken at the national level - that we look beyond mental health as a healthcare issue. It must be integrated with other policy areas. A mental health crisis does not respect geographical borders, even less so in a single market with free movement of people, goods and services. Future interpretations and amendments to European-level regulations on food production, working conditions, consumer protection, posted-workers, cross border patient mobility, and so on, must take full account of the findings and recommendations of the Joint Action, the Framework and the Compass. The recent EU Directive on transparent and predictable working conditions ${ }^{21}$ is an example of a step in the right direction, but should have explicitly recognised its value from a mental health perspective. The fruitful body of EU new governance outputs on mental health should not take second place to voluntary (and brave) newspaper interviews of popular Royals and musicians.

\author{
Adam P. McCann \\ Editor EJCL; Lecturer in Law, University of Exeter, UK \\ a.mccann@exeter.ac.uk
}

21 Directive (EU) 2019/1152 of the European Parliament and of the Council of 20 June 2019 on transparent and predictable working conditions in the European Union. 